\title{
The Morphology and Roughness of Aluminized CoCrAlY Coating By HCPEB
}

$$
\text { Zhiyong } \operatorname{Han}^{1,} \text {, , Jian } \operatorname{Han}^{2,} \text { b }
$$

Adress for both: Tianjin Key Laboratory for Civil Aircraft Airworthiness and Maintenance, Civil Aviation University of China, Tianjin 300300, China

azyhan@cauc.edu.cn, ${ }^{b} 1536232714 @ q q . c o m$

Keywords: Air plasma spray, high current pulse electron beam, micro-structure morphology, roughness

Abstract. In this paper, CoCrAlY coating was prepared on the substrate, Ni-based super alloy (GH4169), using Air Plasma Spray (APS). After deposition, the coating was irradiated by High Current Pulse Electron Beam (HCPEB) with different number of pulse beam. Then the micro-structure of coating surface, like the morphology and roughness, were characterized by scanning electron microscope (SEM) and 3D optical microscope. When the coating treated with 20 times pulse beam, the roughness is $28.02 \mu \mathrm{m}$. Besides, the surface was remelted into a compact appearance with many bulged nodules connected.

\section{Introduction}

MCrAlY coatings( $\mathrm{M}=\mathrm{Ni}, \mathrm{Co})$, as bond coating of thermal barrier coating(TBCs), often applied to critical hot-sections of industrial gas turbine to release residual stress and enforce oxidation resistance ${ }^{[1,2]}$.

In general, bond coating are prepared on the super alloy substrate with air plasma spray. Then ceramic coating, has low thermal conductivity ${ }^{[2]}$, was deposited above it. When operated in the extremely aggressive thermal mechanical environment, TBCs often fail with spallation and crack at the interface between the bond coat and ceramic coat ${ }^{[3,4]}$. It is a layer that called TGO (thermal growth oxidation), plays an essential role in TBCs system ${ }^{[5-7]}$, comes from complex oxidation of bond coating, Therefore, improving the micro-structure of coating surface will be a leading direction of the research of TBCs.

Recently,a new technology named as high current pulsed electron beam (HCPEB) got much attention $^{[8,9]}$. The technology, used as surface modification, has been applied to control the growth and evolution behavior of $\mathrm{TGO}^{[10-12]}$. Professor Cai Jie us irradiated CoCrAlY coating surface with HCPEB. They found that the surface of coating had been remelted completely and replaced with interconnected appearance of protruding nodules ${ }^{[13]}$ that enable TBCs to operate at higher temperatures.

In this paper, the technology of EBVD and HCPEB have been applied in the treatment of bond coat. The effect of this modification will be investigated about the roughness and morphology.

\section{Experimental procedure}

Firstly, the CoCrAlY coating $(23 \mathrm{Co}, 13 \mathrm{Cr}, 0.5 \mathrm{Al}, \mathrm{Y})$ were prepared on grit-blasted Ni-based super alloy substrate $(12 \times 8 \times 2 \mathrm{~mm})$ to a thickness that is about $200 \mu \mathrm{m}$ by using Praxair 3710 type APS (Air Plasma Spray) system. The chemical composition of Ni-based substrate is shown in Table1.

Table 1 GH4169 super alloy chemical composition

\begin{tabular}{c|cccccccc}
\hline $\mathrm{Cr}$ & $\mathrm{Fe}$ & $\mathrm{Nb}+\mathrm{Ta}$ & $\mathrm{Mo}$ & $\mathrm{Ti}$ & $\mathrm{Co}$ & $\mathrm{Al}$ & $\mathrm{Si}$ & $\mathrm{Ni}$ \\
\hline 19.62 & 17.75 & 60 & 1.561 & 0.023 & $<1.0$ & 0.58 & 0.17 & Bal. \\
\hline
\end{tabular}


Then a Al film was deposited on the surface of coating by EB-VD (DZS-500). The thickness of Al film is about $600 \mu \mathrm{m}$. Finally, the composite coating was irradiated by HCPEB (HOPE-1). The current beam voltage was chosen at $16.5 \mathrm{~V}$ while pulse duration is $1.5 \mu \mathrm{s}$. Moreover, the value of energy density is hold at $4 \mathrm{~J} / \mathrm{cm}^{2}$. Comparison was carried out between the number of pulse beam that the times of pulse treatment were decided as 10,20,30 and none

Then a Al film was deposited on the surface of coating by EB-VD (DZS-500). The thickness of Al film is about $600 \mu \mathrm{m}$. Finally, the composite coating was irradiated by HCPEB (HOPE-1). The current beam voltage was chosen at $16.5 \mathrm{~V}$ while pulse duration is $1.5 \mu \mathrm{s}$. Moreover, the value of energy density is hold at $4 \mathrm{~J} / \mathrm{cm}^{2}$. Comparison was carried out between the number of pulse beam that the times of pulse treatment were decided as 10, 20, 30 and none.

The micro-structure of the coating surface was characterized by SEM (Scanning electron microscope, 1530VP) and the chemical composition were tested by EDS equipment above. The roughness of the coating surface were measured 3D optical microscope

\section{Result}

\section{The surface morphology}

Fig. 1 showed the surface morphology of bond coating. Fig(a), initial sample of coating was characterized as lamellar structure with a large amount of unmelted spherical powder and particle, micro-cracks, porosity on the surface. That is a typical morphology coating of coating prepared by APS because CoCrAlY powder were forced to flow to the substrate by high speed air without enough time to melt completely when they were heated by the plasma flame.

The coating treated had been shown in Fig. 1(b,c,d), with a compact appearance of interconnected bulged nodules. Compared with initial coating, the defect of typical coating had been improved, including unmelted particle and porosity. With increasing the pulse of electron beam, the surface of coating became more refine and homogeneous. Moreover, the nodules assembled together, becoming interconnected bigger protruding nodules.

The phenomenon was a likeness to the consequence of Pro Cai experiment. Especially when the times of pulse was 20, the size of nodules was biggest upon others, using different coating modification parameters. Then the crack on the top of coating grew in number. The reason why crack increase was that bond coating irradiated by electron beam had residual stress above top and inside. The stress forced coating surface to crack, which released thermal stress.

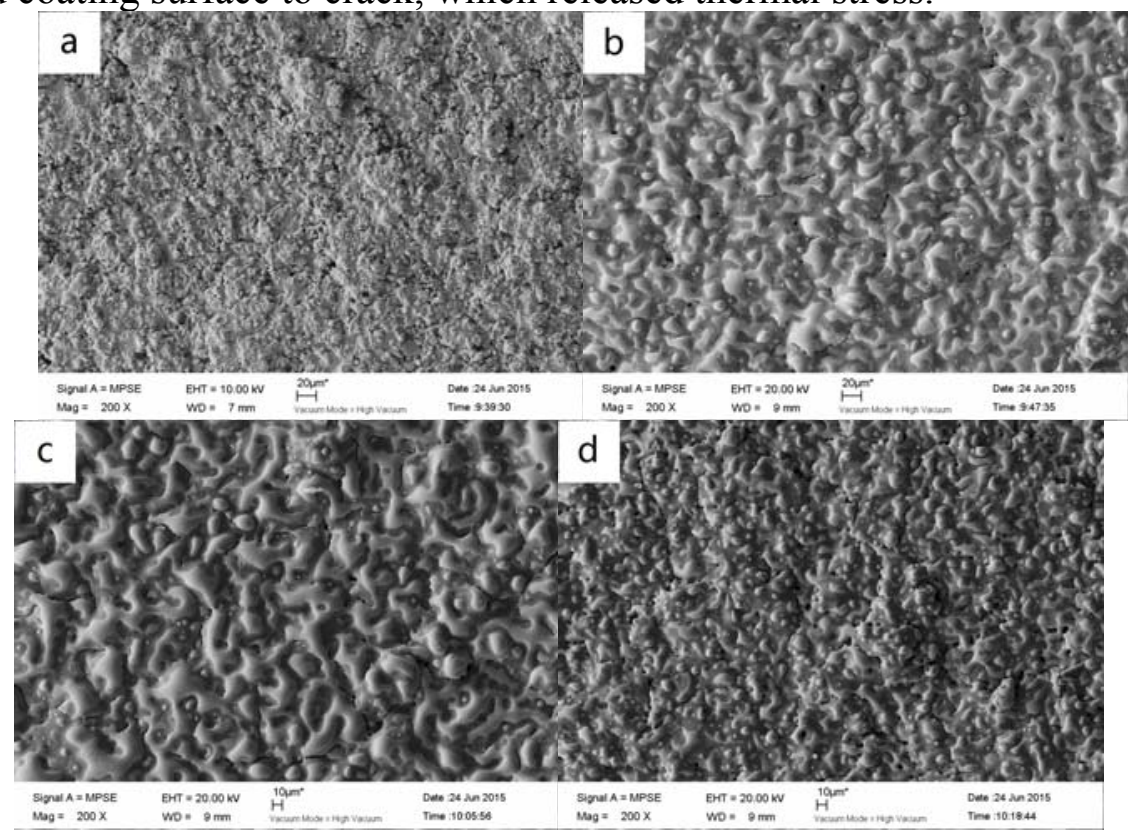

Fig.2 SEM surface of CoCrAlY coating modified by HCPEB after aluminizing (a: initial, b: 10 pulse c: 20 pulse d: 30 pulse ) 


\section{The chemical composition of coat surface}

Fig 3 showed magnification of initial coating.

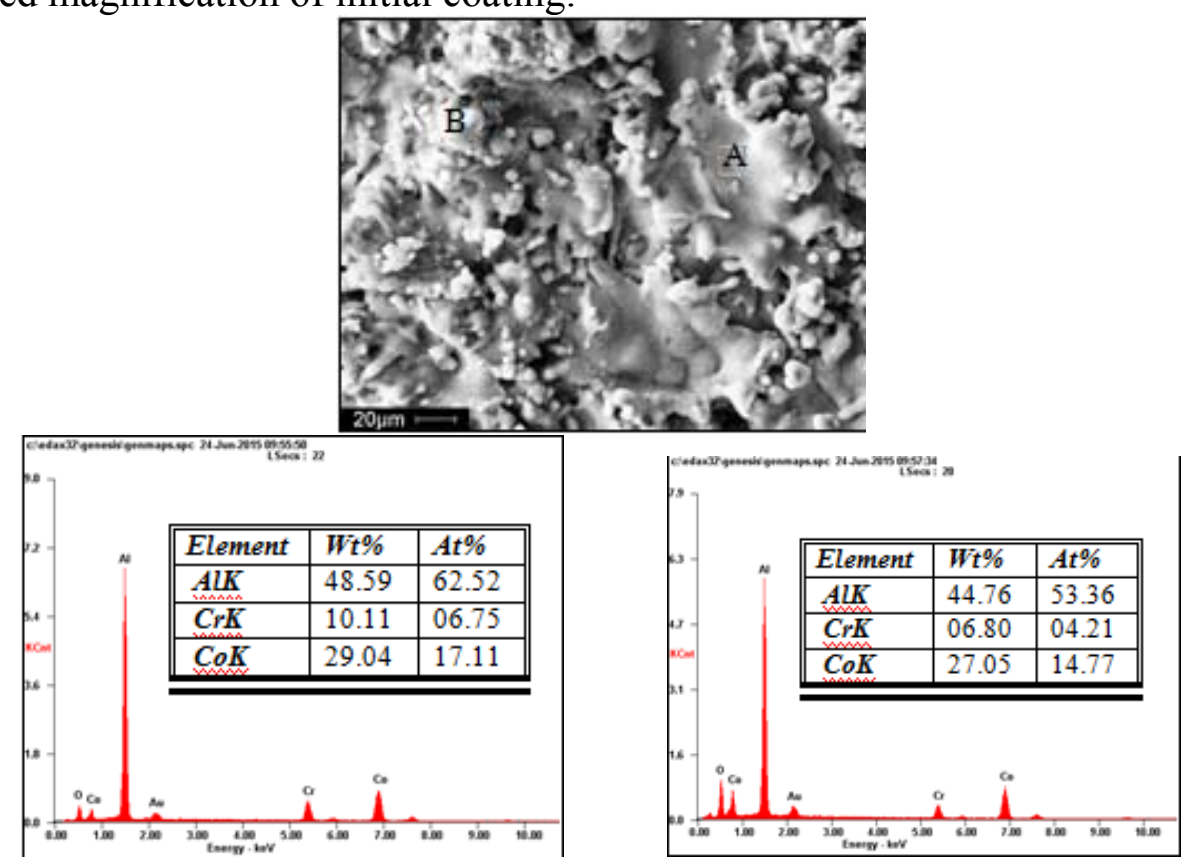

(a)

(b)

Fig.3 Magnification of initial coating(a) SEM,(b) EDS of point A,(c) EDS of point B.

The value of magnification is 1000 . The EDS testing showed that the chemical composition of pit and protrusion. Both of two part shared the same test results. The elemental composition keep stable relatively.

What's more, the percent of Al element proved that Al was more active than others after comparing the chemical composition of the powder of CoCrAlY and surface coating.

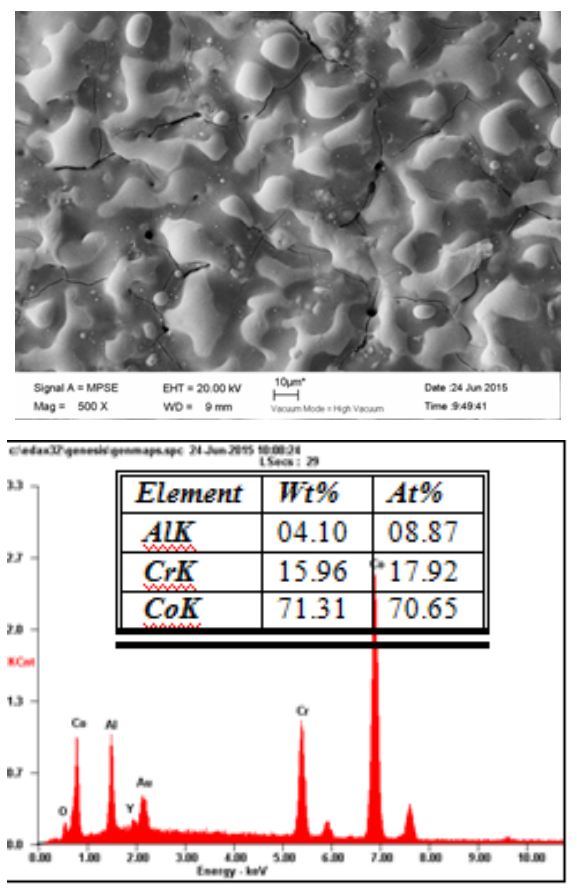

(a) 

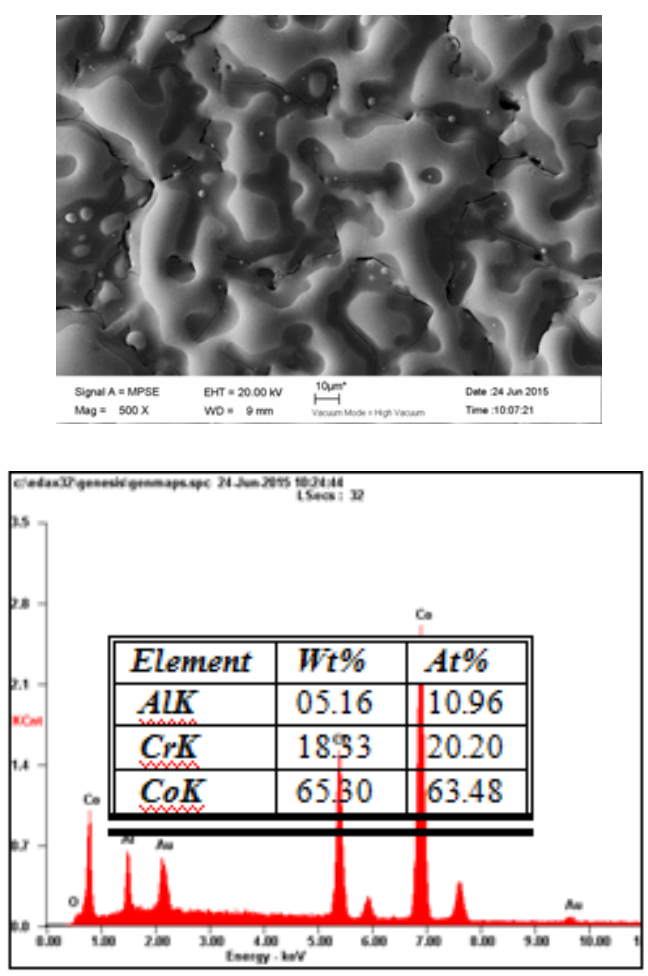

(b)
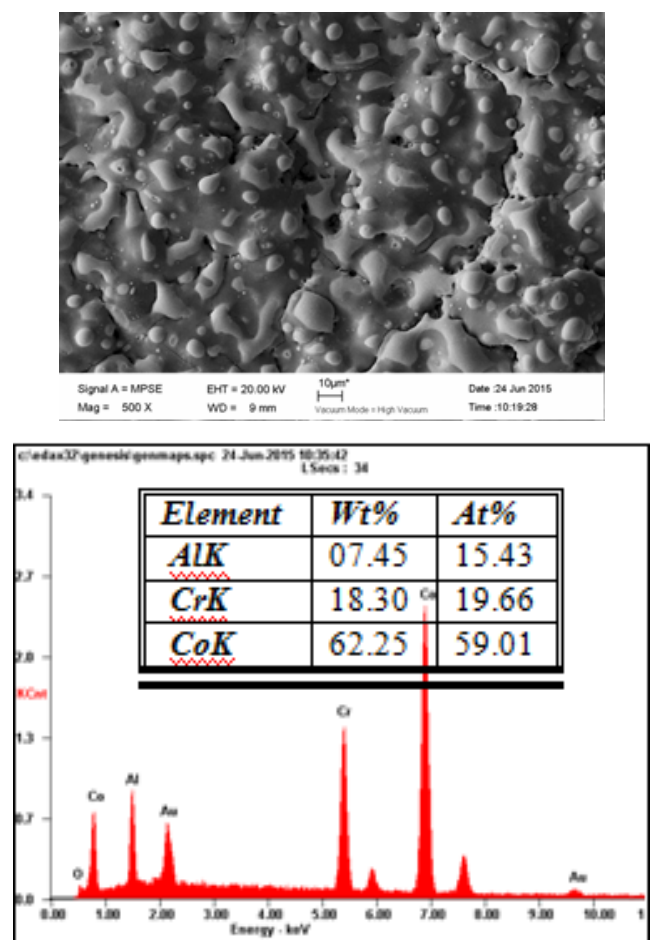

(c)

Fig.4 Magnification and EDS of HCPEB treated CoCrAlY coating after aluminizing, (a: 10 pulses b: 20 pulses c: 30 pulses)

The magnification of HCPEB treated CoCrAlY coating after aluminizing in the Fig 4. The EDS testing results above of coating treated with $\mathrm{HCPEB}$ indicated that the content of element $\mathrm{Al}$ and $\mathrm{Co}$ were obviously different when bonding coating treated with electron beam. The percent of Co content on surface got a large increasing and the Al got sharp reduction, which convinced that HCPEB had improved the chemical composition distribution on the surface of coating.

In addtion, there was no clear evidence that the times of pulse electron beam could change the content of coating surface obviously. 


\section{The roughness of coat surface}

Figure 6 showed the 3D morphology of initial coating characterized by the laser optical microscope, which could measure the value of surface roughness almost. The initial sample is 18.9 $\mu \mathrm{m}$. The image show that sharp peaks andvalleys on the coating top that could be the defeat of coating where the residual stress generate. That would always be the place wghere fatigue failure happened and grew.

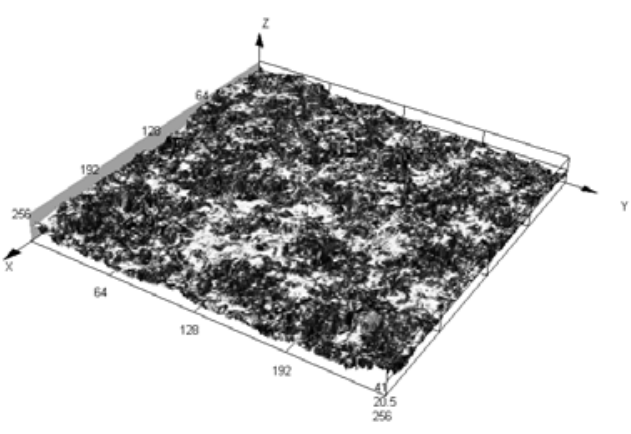

Fig.5 (3D top graph of initial bond coat)

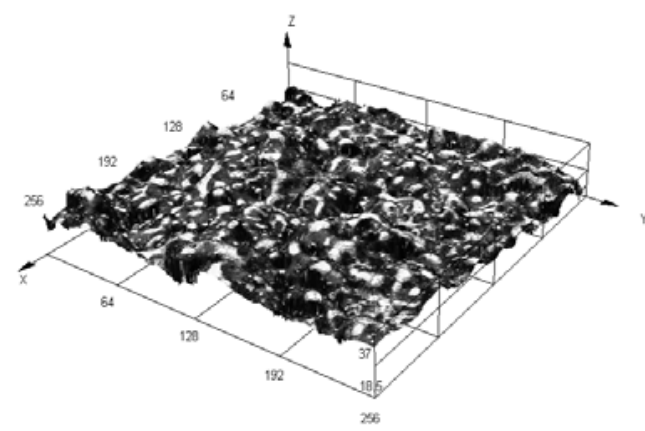

(A)

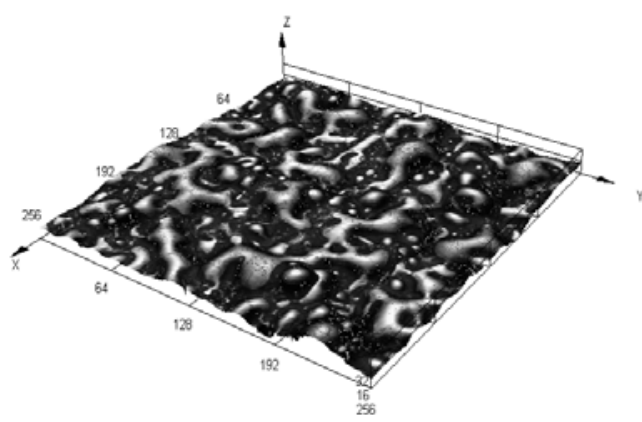

(B)

Fig.6 (3D top graph of bond coat treated by HCPEB after aluminizing A: 10 pulse B: 20 pulse )

Then Fig6 $(\mathrm{A}, \mathrm{B})$ showed the other coatings after treating. They indicated clearly that the more times of electron beam, the more rough surface of coating you could get in a certain range. The value of former roughness was $28.02 \mu \mathrm{m}$, while the latter is higher, which was $42.1 \mu \mathrm{m}$. The section profile of coating surface, Fig7, had a same conclusion with the roughness and it gave a vivid presentation of the testing result.

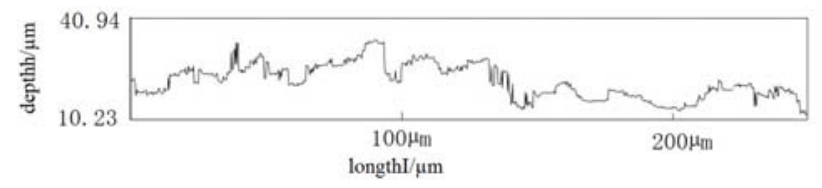

(a) 


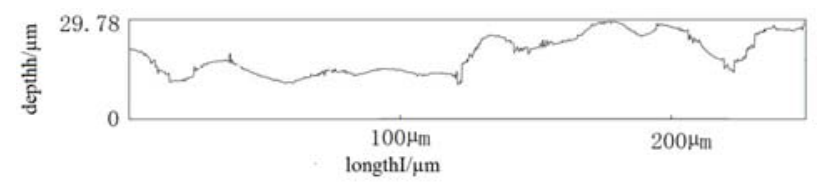

(b)

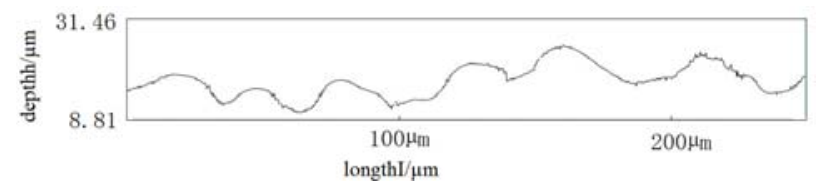

(c)

Fig7 (the section profile of coating surface

a: initial coating b: coating +10 pulses $\mathrm{c}$ : coating +20 pulses)

As we know, bond strength is correlated with mechanical occlusion at the interface. In general, a

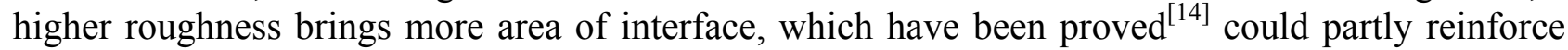
bond strength and that would make the life of TBCs longer at service.

What's more, 3D images of top morphology confirm the consequence of surface SEM. The High Current Pulse Electron Beam is beneficial to optimize the micro-structure of coating. That is apparent that surface of coating after irradiated is more continuous and dense than those not.

\section{Conclusions}

CoCrAlY coating prepared on the substrate with different experiment parameter were investigated. The number of electron beam decided the morphology and roughness of coating surface.

(1) Take the initial coating for comparison, the coating treated by HCPEB after aluminizing remelted and showed compact surface with continuous bulged nodules. Those defects shown in initial coating had disappeared after irradiating by HCPEB. When the coating treated with 20 times pulse electron beam, the sample show the most densification.

(2) With the times of pulse increasing, the roughness of bond coating surface increased. Even though the roughness increased, coating surface kept its compact surface hold. It would have partly positive effects on enhancing bond strength.

\section{Acknowledgements}

The authors are grateful to the funds of Chinese National Natural Science Foundation (U1333107) for financial support.

\section{References}

[1] Czech N, Fietzek H, Juez-Lorenzo M, et al. Studies of the bond-coat oxidation and phase structure of TBCs [J]. Surf Coat Techn, 1999, 113(1/2): 157.

[2] Naumenko D, Shemet V, Singheiser L, et al. Failure mechanisms of thermal barrier coatings on MCrAlY-type bondcoats associated with the formation of the thermally grown oxide[J]. J. Mater. Sci., 2009, 44(7): 1687-1703.

[3] Padture N P, Gell M, Jordan E. Thermal barrier coatings for gas turbine engine application[J]. Science, 2002, 296(5566): 280-284.

[4] Quadakkers W, Shemet V, Sebold D, et al. Oxidation characteristics of a platinized MCrAlY bond coat for TBC systems during cyclic oxidation at $100^{\circ} \mathrm{C}[\mathrm{J}]$. Surf Coat Techn, 2005, 199(1): 77-82. 
[5] Daroonparvar M, Yajid M A M, Yusof N M, et al. Formation of dense and continuous $\mathrm{AL}_{2} \mathrm{O}_{3}$ layer in nano thermal barrier coating systems for the suppression of spinel growth on the $\mathrm{AL}_{2} \mathrm{O}_{3}$ oxide scale during oxidation[J]. J. Alloys Compd., 2013, 571: 205-220.

[6] Mumm D, Evans A, Spitsberg I. Characterization of a cyclic displacement instability for a thermally grown oxide in a thermal barrier system[J]. Acta Mater., 2001, 49(12)

[7] Rabiei A, Evans A. Failure mechanisms associated with the thermally grown oxide in plasma-sprayed thermal barrier coatings[J]. Acta Mater.,2000, 48(15): 3963-3976.

[8] Liyong Ni, Chungen Zhou. Effects of surface modification on thermal cycling lifetime of thermal barrier coatings with HVOF NiCrAIY bond coat. Progress in Natural Science: Materials International, 2012, 22(3): 237-243.

[9] A. Gil, V. Shemet, R. Vassen, M. Subanovic, et al. Effect of surface condition on the oxidation behaviour of MCrAIY coatings. Surface Coatings Technology 201(2006): 3824-3828.

[10] Mei Xianxiu, Liu Xiaofei, Wang Cunxia, et al. Improving oxidation resistance and thermal insulation of thermal barrier coatings by intense pulsed electron beam irradiation. Applied Surface Science, 263(2012): 810-815.

[11] A. Weisenburger, G. Rizzi, A. Scrivani, Georg, Mueller, J.R. Nicholls. Pulsed electron beam treatment of MCrAIY bondcoats for EB-PVD TBC systems. Surface Coatings Technology, 202 (2007): 704-708.

[12] O. P. Kul'ment'eva, A. D. Pogrebnyak. Effect of Pulsed Plasma and High Current Electron Beam Treatments on the Structure and Properties of Nickel Based Coatings. Journal of investigation, 2008, (2)3: 454-473.

[13] Jie Cai, Shengzhi Yang, Le Ji, et al.Surface microstructure and high temperature oxidation resistance of thermal sprayed CoCrAlY coating irradiated by high current pulsed electron beam, Surface\&Coatings Technology, 251(2014): 217-225.

[14] Zhang Xiaofeng, Zhou Kesong, et al. Effect of bond coating surface roughness on properties of high temperature oxidation and mechanical properties in thermal barrier coating. Journal of The Chinese Ceramic Society, 2013, (41): 1674-1678. 